\title{
Ukuran Tubuh Entok di Tiga Kabupaten Provinsi Jawa Tengah
}

\author{
N. Fatmarischa, Sutopo dan S. Johari \\ Fakultas Peternakan dan Pertanian, Universitas Diponegoro, \\ Jl. Prof Sudarto, Semarang 50275, Jawa Tengah \\ E-mail : novemia.f@gmail.com
}

\begin{abstract}
ABSTRAK
Penelitian ini dilakukan untuk mengidentifikasi ukuran-ukuran tubuh entok di Kabupaten (Magelang, Demak dan Pekalongan), Provinsi Jawa Tengah. Materi yang digunakan yaitu 210 ekorentok yang telah dewasa tubuh dengan rerata umur 7 bulan (70 ekor/kabupaten, 35 ekor jantan dan 35 ekor betina) pada masing-masing kabupaten. Variabel ukuran tubuh yang diamati meliputi bobot badan, panjang paruh, lebar paruh,panjang kepala, lingkar kepala, tinggi kepala, panjang leher, lingkar leher, panjang sayap, panjang badan, lingkar badan, tinggi badan, panjang dada, panjang femur, panjang tibia, lingkar tibia, panjang maxilla, dan panjang jari kaki ketiga. Data yang diperoleh dianalisis univariate dan multivariate dengan bantuan software SAS. Jarak Mahalanobis dianalisis menggunakan MEGA 5 (UPGMA) untuk membentuk pohon filogeni. Hasil penelitian menunjukkan bahwa entok jantan dan betina pada masing-masing kabupaten menunjukkan perbedaan $(\mathrm{P}<0,05)$ pada semua variabel yang diamati. Ukuran panjang sayap dan lingkar badan menjadi variabel pembeda pada entok antar kabupaten. Berdasarkan matrik jarak genetik, entok Magelang memiliki kedekatan dengan entok Pekalongan, tetapi berjauhan dengan entok Demak.
\end{abstract}

Kata kunci: karakteristik fenotipik, ukuran tubuh, entok

\section{Body Measurement of Muscovy Duckin Three Regency of Central Java}

\begin{abstract}
The study was conducted to identify the body measurements of Muscovy duck among three regency (Pekalongan, Magelang dan Demak) in Central Java. Material of the experiment was 210 muscovy ducks at 7 months of age (70 birds/regency, 35 males and 35 females). Parameters observed were body weight, bill length, bill width, head length, head circumference, high head, neck length, neck circumference, wing length, body length, breast circumference, body height, breast length, femur length, tibia length, tibia circumference, maxilla length, and length of third toe. Data of body measurement were analyzed through univariate and multivariate using SAS. Whereas the Mahalanobis distance were analyzed using MEGA 5 (UPGMA) to construct the phylogeny tree. Result showed that there were some differences $(P<0,05)$ between male and female of muscovy duck in each regency at all variables. Wing length and breast circumference were the distinguishing variable between regencys. Muscovy duck from Magelang had a closer genetic distance to Pekalongan than Demak.
\end{abstract}

Keywords: body measurement, muscovy duck 


\section{PENDAHULUAN}

Entok merupakan komoditas unggas yang cukup berpotensi untuk dibudidayakan. Bobot dewasa mampu mencapai3-3,5 kg/ekor, sehingga dapat dikembangkan sebagai penghasil daging. Selain itu, entok memiliki daya mengeram yang baik (Balai Pengkajian Teknologi Pertanian, 2010). Keuntungan dari ternak entok yaitu daya tahan tubuh lebih kuat dibandingkan unggas lain, mampu mengubah pakan berkualitas rendah menjadi daging, pemeliharaan tidak memerlukan lahan luas, vaksinasi tidak dilakukan secara rutin (National Departement of Agriculture, 1996; Meulen and Dikken, 2004). Entok memiliki penyebaran yang luas hampir di seluruh kawasan Indonesia. Penyebaran entok juga terjadi secara merata di Jawa Tengah dengan populasi yang berbeda di tiap kabupaten. Perbedaan populasi entok di tiap kabupaten dapat dipengaruhi oleh ketersediaan lahan, pakan, dan kondisi lingkungan.

Penelitian yang lebih komprehensif mengenai ukuran tubuh perlu dilakukan agar dapat diperoleh data entok secara spesifik di lokasi tertentu. Keragaman fenotipik entok antar wilayah dapat diketahui melalui ukuran-ukuran tubuh entok. Ukuran-ukuran tubuh tersebut dapat digunakan sebagai data kajian morfometrik pada entok sebagai analisis dasar untuk mengetahui perbedaan genetik dan karakteristiknya. Yakubu dan Ugbo (2011) melaporkan bahwa perbandingan fenotipik berdasarkan ukuran tubuh dapat memberikan petunjuk perbedaan genetik diantara populasi dengan kriteria tertentu. Penelitian morfometri entok pernah dilakukan Yakubu (2011)pada entok Afrika dewasa meliputi bobot badan, panjang badan, lingkar badan, lingkar paha atau tibia, panjang paruh, panjang leher, panjang kaki, dan panjang sayap.

Pengukuran tubuh entok di tiga kabupaten yang berbeda dapat juga digunakan untuk mengetahui jarak genetik. Brahmantiyo et al. (2003) menyatakan jarak genetik sederhana dapat dilakukan dengan penentuan pola perbedaan sifat fenotipik pada setiap individu. Jarak genetik adalah tingkat perbedaan gen (perbedaan genomik) antara populasi atau spesies yang diukur oleh beberapa kuantitas numerik (Nei, 1987). Penelitian ini bertujuan untuk mengetahui keragaman fenotipik entok berdasarkan morfometrik sehingga dapat diketahui karakteristik entok antar daerah.

\section{MATERI DAN METODE}

Penelitian mengenai keragaman fenotipik entok di Jawa Tengah dilakukan dengan mengambil sampel entok dari tiga kabupaten yaitu Magelang, Demak dan Pekalongan. Lokasi ditentukan berdasarkan populasi tertinggi pada bagian utara, selatan, dan timur. Masing-masing kabupaten diambil 70 ekor entok (35 ekor jantan dan 35 ekor betina) dengan rerata umur 7 bulan.

Parameter morfometrik meliputi bobot badan, panjang paruh, lebar paruh, panjang kepala, tinggi kepala, diameter kepala, panjang leher, diameter leher, panjang sayap, panjang badan, lingkar badan, tinggi badan, panjang dada, panjang femur, panjang tibia, lingkar tibia, panjang metatarsus, panjang jari kaki ke-3 (Ogah, 2009; Yakubu, 2011). Data pengukuran tubuh diambil dari masing-masing entok jantan dan betina sedangkan data lainnya merupakan penggabungan dari entok jantan dan betina. Pengukuran tubuh entok menggunakan jangka sorong, pita ukur, dan timbangan.

\section{Analisis data}

Analisis data pengukuran entok menggunakan software Statistical Analysis Sistem (SAS, 1990). Proc means untuk mengetahui nilai rata-rata dan standar deviasi setiap ukuran tubuh dan bobot badan. Proc t-test untuk mengetahui perbedaan penampilan morphometrik antar entok pada lokasi yang berbeda. Proc princomp untuk mengetahui penentuan peta penyebaran dan menentukan variabel pembeda entok pada lokasi yang berbeda. Proc discrim untuk mengetahui persentase kesamaan dan jarak 
genetik entok pada lokasi yang berbeda. Hasil analisis diskriminan dimasukkan ke dalam software MEGA 5 untuk menggambarkan pohon fenogram pada entok dari kabupaten yang berbeda.

\section{HASIL DAN PEMBAHASAN}

\section{Perbedaan ukuran tubuh entok antar jenis kelamin tiap kabupaten}

Seperti yang ditunjukkan pada Tabel 1, dapat diketahui bahwa entok jantan memiliki ukuran-ukuran tubuh yang lebih besar $(\mathrm{P}<0,05)$ dibandingkan entok betina. Hasil analisis uji $\mathrm{t}$ juga menunjukkan bahwa terdapat perbedaan nyata $(\mathrm{P}<0,05)$ antara entok jantan dan betina pada semua variabel pengukuran (bobot badan, panjang paruh, lebar paruh, panjang kepala, tinggi kepala, diameter kepala, panjang leher, diameter leher, panjang sayap, panjang badan, lingkar badan, tinggi badan, panjang dada, panjang femur, panjang tibia, lingkar tibia, panjang metatarsus, panjang jari kaki ke-3) di Kabupaten Demak, Kabupaten Magelang dan Kabupaten Pekalongan. Ogah et al. (2009) melaporkan bahwa entok jantan memiliki ukuran tubuh yang lebih tinggi $(\mathrm{P}<0,05)$ dibandingkan dengan ukuran tubuh entok betina. Oleh karena itu, Yakubu (2011) menyatakan bahwa ternak jantan dapat dimanfaatkan sebagai penghasil daging sedangkan ternak betina digunakan untuk program pemuliaan. Penelitian Raji et al. (2009) menyatakan bahwa bobot badan dan ukuran tubuh yang berbeda antara jantan dan betina disebabkan karena efisiensi dan konversi pakan yang berbeda antara keduanya. Brahmantiyo et al. (2002) melaporkan bahwa panjang sayap menunjukkan perbedaan yang nyata antara entok jantan dan betina, sedangkan pada penelitian ini variabel pembeda ditunjukkan pada panjang sayap dan lingkar badan.

\section{Perbedaan ukuran tubuh jantan dan betina di tiga kabupaten}

Pada entok jantan ditemukan adanya perbedaan $(\mathrm{P}<0,05)$ pada hampir semua variabel pengukuran kecuali pada lebar paruhdan panjang sayap (Tabel 1). Ukuranukuran tubuh tertinggi didapatkan pada entok di Kabupaten Demak dan Magelang. Hasil yang sama juga ditunjukkan pada entok betina di tiga kabupaten berbeda yaitu pada semua variabel yang diukur kecuali bobot badan, panjang badan, tinggi badan dan lingkar tibia. Perbedaan ukuran-ukuran tubuh tersebut dimungkinkan karena manajemen pmeliharaan di daerah tersebut. Seperti yang dikemukakan Legates and Warwick (1990) bahwa penampilan tubuh seekor ternak dapat dipengaruhi oleh faktor keturunan dan lingkungan ternak tersebut sejak terjadinya pembuahan hingga dilakukan pengukuran tubuh. Selain itu, faktor pakan serta sistem pemeliharaan turut menunjang hasil ukuran tubuh pada daerah tersebut. Variasi dan respon sifat-sifat kuantitatif terhadap lingkungan dapat memberi informasi mengenai perbedaan ukuran tubuh di masing-masing daerah.Yakubu (2013) melaporkan bahwa variasi fenotipik yang tinggi diindikasikan karena tingginya variasi genetik berdasarkan respon seleksi.

Ukuran tubuh entok jantan antar tiga kabupaten memiliki hasil analisis yang berbeda $(\mathrm{P}<0,05)$, kecuali lebar paruh dan panjang sayapsedangkan entok betina menunjukkan perbedaan kecuali pada variabel bobot badan dan panjang badan. Hal tersebut dikarenakan ukuran-ukuran tubuh antara jantan dan betina yang berbeda. Ogah (2009) melaporkan bahwa terdapat perbedaan pada variabel bobot badan, panjang badan, lingkar badan, tinggi badan, panjang paruh, tinggi paruh, lebar paruh, panjang tibia, panjang kepala, lingkar kepala, panjang leher, dan panjang sayap antara jantan dan betina.

\section{Variabel pembeda entok di tiga kabupaten}

Hasil analisis komponen utama (PC) pada Tabel 2 menunjukkan bahwa lingkar 
Tabel 1. Hasil ukuran tubuh entok di tiga kabupaten Jawa Tengah

\begin{tabular}{|c|c|c|c|c|c|c|}
\hline \multirow{2}{*}{ Variabel } & \multicolumn{2}{|c|}{ Demak } & \multicolumn{2}{|c|}{ Magelang } & \multicolumn{2}{|c|}{ Pekalongan } \\
\hline & Jantan & Betina & Jantan & Betina & Jantan & Betina \\
\hline Bobot badan & $2,94 \pm 0,24^{\mathrm{a}, \mathrm{m}}$ & $1,77 \pm 0,21^{\mathrm{b}}$ & $2,75 \pm 0,48^{\mathrm{e}, \mathrm{n}}$ & $1,70 \pm 0,28^{\mathrm{f}}$ & $2,66 \pm 0,39^{1, \mathrm{n}}$ & $1,77 \pm 0,27^{j}$ \\
\hline Panjang paruh & $6,05 \pm 0,37^{\mathrm{a}, \mathrm{n}}$ & $5,32 \pm 0,27^{\mathrm{b}, \mathrm{t}}$ & $6,18 \pm 0,34^{\mathrm{e}, \mathrm{n}}$ & $5,58 \pm 0,31^{\mathrm{f}, \mathrm{s}}$ & $6,34 \pm 0,19^{\mathrm{i}, \mathrm{m}}$ & $5,44 \pm 0,25^{\mathrm{j}, \mathrm{t}}$ \\
\hline Lebar paruh & $2,61 \pm 0,23^{\mathrm{a}}$ & $2,50 \pm 0,28^{\mathrm{b}, \mathrm{s}}$ & $2,62 \pm 0,15^{\mathrm{e}}$ & $2,38 \pm 0,14^{\mathrm{f}, \mathrm{t}}$ & $2,58 \pm 0,17^{\mathrm{i}}$ & $2,37 \pm 0,21^{\mathrm{j}, \mathrm{t}}$ \\
\hline Panjang kepala & $6,15 \pm 1,15^{\mathrm{a}, \mathrm{m}}$ & $5,50 \pm 0,83^{\mathrm{b}, \mathrm{s}}$ & $5,69 \pm 0,43^{\mathrm{e}, \mathrm{n}}$ & $5,03 \pm 0,38^{\mathrm{f}, \mathrm{t}}$ & $5,71 \pm 0,46^{\mathrm{i}, \mathrm{n}}$ & $4,94 \pm 0,46^{\mathrm{j}, \mathrm{t}}$ \\
\hline Lingkar kepala & $16,65 \pm 1,02^{\mathrm{a}, \mathrm{m}}$ & $14,15 \pm 0,48^{\mathrm{b}, \mathrm{s}}$ & $15,97 \pm 0,71^{\mathrm{e}, \mathrm{n}}$ & $13,99 \pm 0,53^{\mathrm{f}, \mathrm{s}, \mathrm{t}}$ & $15,62 \pm 0,68^{\mathrm{i}, \mathrm{n}}$ & $13,75 \pm 0,61^{\mathrm{j}, \mathrm{t}}$ \\
\hline Tinggi kepala & $5,35 \pm 0,37^{\mathrm{a}, \mathrm{m}}$ & $4,63 \pm 0,46^{\mathrm{b}, \mathrm{s}}$ & $4,83 \pm 0,36^{\mathrm{e}, \mathrm{n}}$ & $4,28 \pm 0,19^{\mathrm{f}, \mathrm{t}}$ & $4,80 \pm 0,20^{\mathrm{i}, \mathrm{n}}$ & $4,34 \pm 0,29^{\mathrm{j}, \mathrm{t}}$ \\
\hline Panjang leher & $19,59 \pm 2,14^{\mathrm{a}, \mathrm{n}}$ & $15,03 \pm 1,81^{\mathrm{b}, \mathrm{t}}$ & $20,54 \pm 1,48^{\mathrm{e}, \mathrm{m}}$ & $17,09 \pm 1,24^{\mathrm{f}, \mathrm{s}}$ & $18,97 \pm 1,56^{\mathrm{i}, \mathrm{n}}$ & $16,84 \pm 1,47^{\mathrm{j}, \mathrm{s}}$ \\
\hline Lingkar leher & $11,25 \pm 0,79^{\mathrm{a}, \mathrm{m}}$ & $9,11 \pm 0,86^{\mathrm{b}, \mathrm{s}}$ & $10,56 \pm 0,68^{\mathrm{e}, \mathrm{n}}$ & $8,35 \pm 0,43^{\mathrm{f}, \mathrm{t}}$ & $10,07 \pm 0,94^{\mathrm{i}, \mathrm{o}}$ & $8,31 \pm 0,62^{\mathrm{j}, \mathrm{t}}$ \\
\hline Panjang sayap & $33,25 \pm 3,51^{\mathrm{a}}$ & $27,85 \pm 2,50^{\mathrm{b}, \mathrm{t}}$ & $33,60 \pm 2,51^{\mathrm{e}}$ & $29,96 \pm 2,56^{\mathrm{f}, \mathrm{s}}$ & $32,77 \pm 2,01^{\mathrm{i}}$ & $29,05 \pm 2,35^{\mathrm{j}, \mathrm{s}}$ \\
\hline Panjang badan & $26,58 \pm 2,75^{\mathrm{a}, \mathrm{m}, \mathrm{n}}$ & $22,06 \pm 2,53^{\mathrm{b}}$ & $27,34 \pm 2,61^{\mathrm{e}, \mathrm{m}}$ & $21,79 \pm 1,23^{\mathrm{f}}$ & $25,67 \pm 1,33^{\mathrm{i}, \mathrm{n}}$ & $21,43 \pm 1,84^{j}$ \\
\hline Lingkar badan & $42,34 \pm 2,89^{\mathrm{a}, \mathrm{m}}$ & $33,63 \pm 2,84^{\mathrm{b}, \mathrm{s}}$ & $37,47 \pm 2,05^{\mathrm{e}, \mathrm{n}}$ & $31,30 \pm 2,19^{\mathrm{f}, \mathrm{t}}$ & $36,30 \pm 1,60^{\mathrm{i}, \mathrm{o}}$ & $30,66 \pm 2,83^{\mathrm{j}, \mathrm{t}}$ \\
\hline Tinggi badan & $10,75 \pm 1,26^{\mathrm{a}, \mathrm{m}, \mathrm{n}}$ & $9,53 \pm 1,50^{\mathrm{b}}$ & $11,19 \pm 0,78^{\mathrm{e}, \mathrm{m}}$ & $9,14 \pm 0,61^{\mathrm{f}}$ & $10,47 \pm 0,88^{\mathrm{i}, \mathrm{n}}$ & $9,49 \pm 0,29^{j}$ \\
\hline Panjang dada & $19,81 \pm 2,07^{\mathrm{a}, \mathrm{m}}$ & $15,38 \pm 1,74^{\mathrm{b}, \mathrm{s}}$ & $18,82 \pm 1,39^{\mathrm{e}, \mathrm{n}}$ & $15,17 \pm 0,96^{\mathrm{fs}, \mathrm{t}}$ & $17,60 \pm 1,85^{\mathrm{i}, \mathrm{o}}$ & $14,61 \pm 1,07^{\mathrm{j}, \mathrm{t}}$ \\
\hline Panjang femur & $7,78 \pm 0,54^{\mathrm{a}, \mathrm{o}}$ & $7,15 \pm 0,49^{\mathrm{b}, \mathrm{t}}$ & $8,54 \pm 0,76^{\mathrm{e}, \mathrm{n}}$ & $7,72 \pm 0,47^{\mathrm{f}, \mathrm{s}}$ & $9,14 \pm 0,54^{\mathrm{i}, \mathrm{m}}$ & $7,73 \pm 0,46^{\mathrm{j}, \mathrm{s}}$ \\
\hline Panjang tibia & $11,14 \pm 0,65^{\mathrm{a}, \mathrm{n}}$ & $9,66 \pm 0,49^{\mathrm{b}, \mathrm{t}}$ & $11,66 \pm 0,75^{\mathrm{e}, \mathrm{m}}$ & $10,38 \pm 0,90^{\mathrm{f}, \mathrm{s}}$ & $11,85 \pm 0,57^{\mathrm{i}, \mathrm{m}}$ & $9,92 \pm 0,68^{\mathrm{j}, \mathrm{t}}$ \\
\hline Lingkar tibia & $5,93 \pm 0,56^{\mathrm{a}, \mathrm{m}}$ & $4,83 \pm 0,48^{\mathrm{b}}$ & $5,43 \pm 0,41^{\mathrm{e}, \mathrm{n}}$ & $4,67 \pm 0,43^{\mathrm{f}}$ & $5,21 \pm 0,51^{\mathrm{i}, \mathrm{n}}$ & $4,64 \pm 0,42^{\mathrm{j}}$ \\
\hline $\begin{array}{l}\text { Panjang } \\
\text { maxilla }\end{array}$ & $5,01 \pm 0,64^{\mathrm{a}, \mathrm{n}}$ & $4,32 \pm 0,48^{\mathrm{b}, \mathrm{t}}$ & $5,36 \pm 0,51^{\mathrm{e}, \mathrm{m}}$ & $4,62 \pm 0,59^{\mathrm{f}, \mathrm{s}}$ & $5,51 \pm 0,51^{\mathrm{i}, \mathrm{m}}$ & $4,28 \pm 0,53^{\mathrm{j}, \mathrm{t}}$ \\
\hline $\begin{array}{l}\text { Panjang jari } \\
\text { kaki ke } 3\end{array}$ & $7,26 \pm 0,68^{\mathrm{a}, \mathrm{n}}$ & $6,32 \pm 0,49^{\mathrm{b}, \mathrm{t}}$ & $7,54 \pm 0,55^{\mathrm{e}, \mathrm{n}}$ & $6,87 \pm 0,73^{\mathrm{f}, \mathrm{s}}$ & $8,07 \pm 0,62^{\mathrm{i}, \mathrm{m}}$ & $6,65 \pm 0,52^{\mathrm{j}, \mathrm{s}}$ \\
\hline
\end{tabular}

\section{Keterangan :}

$(\mathrm{a}, \mathrm{b})(\mathrm{e}, \mathrm{f})(\mathrm{i}, \mathrm{j})$ superskrippada baris yang sama menunjukkan berbeda nyata $(\mathrm{P}<0,05)$;

$(\mathrm{m}, \mathrm{n}, \mathrm{o})$ superskrip yang berbeda pada jenis kelamin jantan di kabupaten berbeda menunjukkan perbedaan yang nyata $(\mathrm{P}<0,05)$;

$(\mathrm{s}, \mathrm{t}, \mathrm{u})$ superskrip yang berbeda pada jenis kelamin betina di kabupaten berbeda menunjukkan perbedaan yang nyata $(\mathrm{P}<0,05)$;

Tabel 2. Principal Component entok dari tiga kabupaten di Jawa Tengah

\begin{tabular}{lcc}
\hline \multicolumn{1}{c}{ Variabel Pengamatan } & PC 1 & PC 2 \\
\hline Bobot badan & 0,08 & 0,003 \\
Panjang paruh & 0,05 & 0,05 \\
Lebar paruh & 0,02 & $-0,002$ \\
Panjang kepala & 0,08 & $-0,03$ \\
Lingkar kepala & 0,18 & $-0,04$ \\
Tinggi kepala & 0,05 & $-0,04$ \\
Panjang leher & 0,24 & 0,33 \\
Lingkar leher & 0,17 & $-0,08$ \\
Panjang sayap & 0,39 & $\mathbf{0 , 6 1}$ \\
Panjang badan & 0,40 & 0,19 \\
Lingkar badan & $\mathbf{0 , 6 3}$ & $-0,63$ \\
Tinggi badan & 0,12 & 0,06 \\
Panjang dada & 0,32 & $-0,03$ \\
Panjang femur & 0,06 & 0,15 \\
Panjang tibia & 0,11 & 0,15 \\
Lingkar tibia & 0,07 & 0,09 \\
Panjang maxilla & 0,06 & $-0,03$ \\
Panjang jari kaki ke 3 & 0,07 & 0,09 \\
\hline
\end{tabular}


Tabel 3. Jarak genetik entok di tiga kabupaten Jawa Tengah

\begin{tabular}{llll}
\hline \hline Kabupaten & Demak & Magelang & Pekalongan \\
\hline Demak & 0 & 7,72587 & 10,38219 \\
Magelang & 7,72587 & 0 & 1,77490 \\
Pekalongan & 10,38219 & 1,77490 & 0 \\
\hline
\end{tabular}

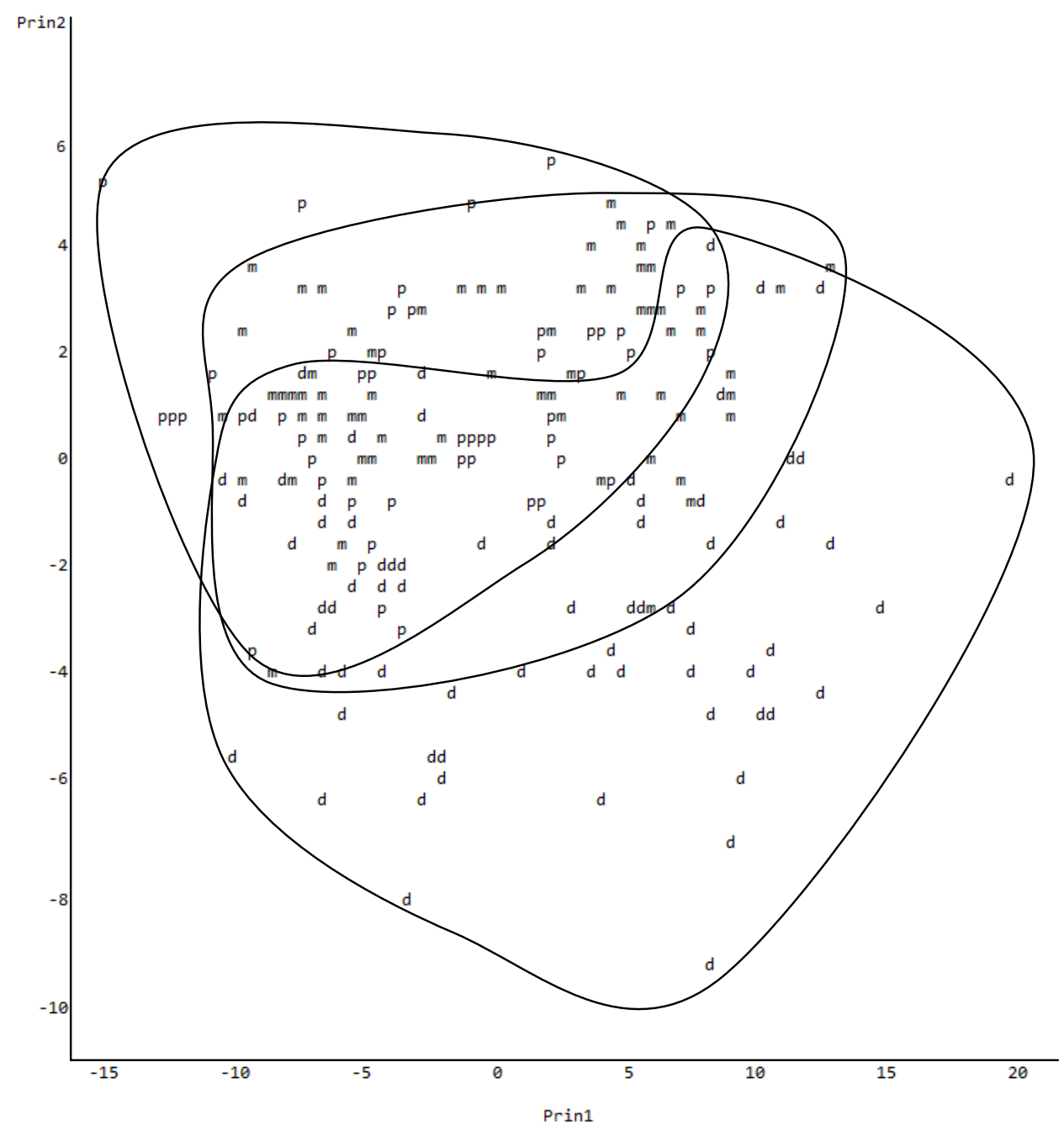

Gambar 1. Hasil peta pengelompokkan entok

(Keterangan : $d=$ entok Kabupaten Demak, $m=$ entok Kabupaten Magelang $\mathrm{p}=$ entok Kabupaten Pekalongan)

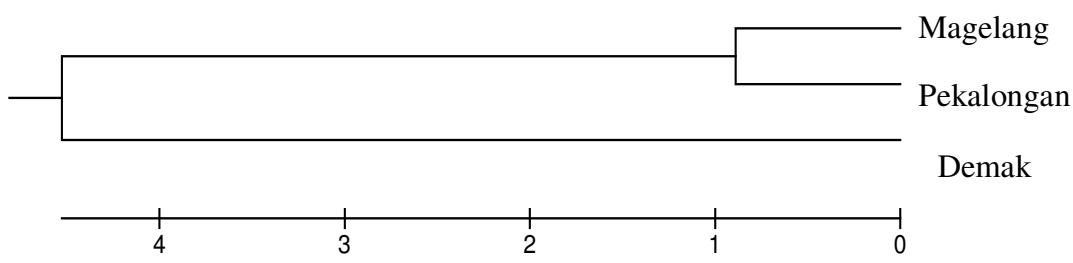

Gambar 2. Pohon filogenetik entok kabupaten Demak, Magelang dan Pekalongan 
badan dan panjang sayap memiliki angka positif dengan nilai 0,63 dan 0,61. Angka tersebut dapat dinyatakan sebagai variabel pembeda entok antar kabupaten dalam penelitian ini. Sejalan dengan penelitian Yakubu (2011) yang menyatakan bahwa panjang sayap dapat dijadikan koefisien standar pada ukuran tubuh entok Afrika. Brahmantyo et al. (2002) melaporkan bahwa pada entok impor dan entok lokal, panjang sayap memberikan pengaruh terbesar terhadap ukuran tubuh.

Hasil analisis komponen utama (PC1) menunjukkan angka yang lebih tinggi dibandingkan PC 2 karena tidak terdapat variabel yang bernilai negatif. Pada PC 2 terdapat beberapa variabel yang memiliki angka negatif, sehingga variabel-variabel tersebut kurang tepat untuk dijadikan komponen pembeda entok antar kabupaten. Ogah et al. (2009) menyebutkan bahwa pada PC1 selalu didapatkan angka variasi yang lebih tinggi. Ditegaskan oleh Udeh dan Ogbu (2011) bahwa angka yang lebih tinggi pada analisis komponen utama dapat digunakan sebagi acuan/standar utama pembeda.

\section{Peta pengelompokkan entok di tiga kabupaten Jawa Tengah}

Berdasarkan Gambar 1 dapat diuraikan pengelompokkan entok di tiga kabupaten. Entok di Kabupaten Demak lebih banyak terletak di sebelah kanan axis Y dan di bawah axis X. Entok Kabupaten Magelang dan Pekalongan banyak menyebar di atas axis $\mathrm{X}$ dan di sebelah kiri axis Y. Hasil tersebut menunjukkan bahwa entok Magelang dan Pekalongan memiliki hubungan kekerabatan yang dekat dan memiliki hubungan yang jauh terhadap entok Demak.

Analisis canonical banyak digunakan untuk mengetahui suatu pola penyebaran bangsa dalam suatu populasi. Yakubu et al. (2011) melaporkan bahwa analisis canonical berfungsi untuk mengetahui penyebaranentok pada daerah berbeda melalui persamaan ukuran-ukuran tubuh diantara populasi entok yang dapat dijadikan sebagai indikasi perbedaan dalam suatu bangsa.Kabupaten Demak memiliki penyebaran ukuran relatif tubuh yang lebih besar dibandingkan kabupaten lain. Hal ini diduga karena respon genetik yang berbeda.

\section{Jarak genetik entok berdasarkan morfometrik di tiga kabupaten Jawa Tengah}

Berdasarkan hasil analisis diskriminan melalui pendekatan matrik Mahalanobis menunjukkan bahwa entok Magelang memiliki kedekatan dengan entok Pekalongan (Gambar 2). Nei (1987) menyatakan bahwa pengukuran jarak genetik untuk karakter kuantitatif yang paling sering digunakan adalah dengan menerapkan statistik Mahalanobis. Nilai matrik jarak genetik antara masing-masing kabupaten disajikan pada Tabel 3 yang digunakan untuk membuat konstruksi pohon filogenetik (Gambar2). Jarak genetik dapat digambarkan melalui pohon filogenetik. Nei (1987) menyatakan bahwa pohon filogenetik yang menggambarkan jalur evolusioner dari kelompok spesies atau populasi diberi nama pohon spesies atau pohon populasi. Berdasarkan nilai jarak genetiknya, entok Magelang dan Pekalongan memiliki nilai terkecil sebesar 1,7749 sedangkan nilai terbesar adalah antara entok Demak dan Pekalongan sebesar 10,3822. Hasil tersebut dapat dimaknai semakin kecil angka yang ditunjukkan maka semakin dekat pula hubungan kekerabatan yang dimiliki.

Hasil analisis diskriminan dapat dipengaruhi oleh beberapa hal, diantaranya yaitu lokasi pemeliharaan yang berdekatan. Muzani et al. (2005) melaporkan bahwa tingginya nilai kesamaan pada itik Cihateup dan Cirebon dikarenakan daerah pemeliharaan yang berdekatan. Brahmantiyo et al. (2003) menyarankan bahwa seleksi yang baik perlu dilakukan untuk mendapatkan hasil yang lebih baik untuk ukuran-ukuran morfologis. 


\section{SIMPULAN}

Entok jantan di masing-masing kabupaten memiliki ukuran tubuh yang lebih tinggi dibandingkan entok betina. Pada entok jantan antar kabupaten memiliki perbedaan pada hampir semua variabel yang diukur kecuali pada variabel lebar paruh dan panjang sayap. Variabel pembeda yang memiliki nilai positif tertinggi pada entok dari tiga kabupaten yaitu lingkar badan dan panjang sayap. Analisis diskriminan melalui pendekatan jarak Mahalanobis menunjukkan bahwa entok Magelang memiliki kedekatan dengan entok di Pekalongan, yang terpisah dengan Demak.

\section{DAFTAR PUSTAKA}

Balai Pengkajian Teknologi Pertanian. 2010. Budidaya Ternak Itik. Badan Peneliti dan Pengembangan Pertanian, Bandung.

Brahmantyo, B., R. H. Mulyono, dan A. Sutisna. 2002. Ukuran dan bentuk itik pekin (Anas platyrhynchos), entok impor dan entok lokal (Cairina moschata). Dalam: Lokakarya Nasional Pengelolaan dan Perlindungan Sumber Daya Genetik di Indonesia: Manfaat Ekonomi untuk Mewujudkan Ketahanan Nasional. Balai Penelitian Ternak, Bogor. Hal.266-272.

Brahmantiyo, B., L. H. Prasetyo, A.R. Setioko, dan R. H. Mulyono. 2003. Pendugaan jarak genetik dan faktor peubah pembeda galur Itik (Alabio, Bali, Khaki Campbell, Mojosari dan Pegagan) melalui Analisis Morfometrik. Jurnal Ilmu Ternak dan Veteriner 8: 1-7.

Legates, J. E. and Warwick. 1990. Breeding and Improvement of Farm Animals. $8^{\text {th }}$ Ed. McGraw-Hill Publising Company, New York.

Meulen, S. J. and D. G. Dikken. 2004. Duck Keeping in the Tropics. Agromisa Foundation, Wageningen.
National Department of Agriculture. 1996. Muscovy Ducks (makoue). Agricultural Research Council, Pretoria.

Nei, M. 1987. Molecular Evolutionary Genetics. Colombia University Press, New York.

Ogah, D. M. 2009. Analysis of morphological traits of geographically separated population of indigenous muscovy duck (Cairina moschata). International Journal of Poultry Science 8 (2): 179-182.

Ogah, D. M., A. A. Alaga, and M. O. Momoh. 2009. Principal component factor analysis of the morphostructural traits of Muscovy duck. International Journal of Poultry Science 8 (11): 1100-1103.

Raji, A. O., J. U. Igwebuike, and M. T. Usman. 2009. Zoometrical body measurements and their relation with live weight in matured local Muscovy ducks in Borno state Nigeria. Journal of Agricultural and Biological Science 4 (3): 58-62.

SAS. 1990. SAS/STAT Users Guide Version 6. Fourth Edition. Volume 2. SAS Campus Drive. Cary. North Carolina 27513, USA.

Udeh, I. and C. C. Ogbu. 2011. Principal component analysis ofbody measurements in three strainsof broiler chicken. Science World Journal 6 (2): 11-14.

Yakubu, A. 2011. Discriminant analysis of sexual dimorphism inmorphological traits of african Muscovy ducks. Arch. Zootec 60 (232): 1115-1123.

Yakubu, A. 2013. Characterisation of the local Muscovy duck in Nigeria and its potential for egg and meat production. World's Poultry Science Journal69: 931-938.

Yakubu, A. and S. B. Ugbo. 2011. An assessment of biodiversity in morphological traits of Muscovy ducks in Nigeriausing discriminant analysis. In: International Proceedings of Chemical, Biological and Environmental Engineering. pp 389-391.

Yakubu, A., F. G. Kaankuka, and S.B. Ugbo. 2011. Morphometric traits of Muscovy ducks from two agro-ecological zones of Nigeria. Tropicultura 29 (2): 121-124. 